\title{
Artelogie
}

Recherche sur les arts, le patrimoine et la littérature de l'Amérique latine

$9 \mid 2016$

Horizons et perspectives de la culture en Colombie (1990-2015)

\section{Colombia y su interminable paternalismo feudal}

\section{Carlos Fajardo}

\section{(2) OpenEdition}

\section{Journals}

Edición electrónica

URL: http://journals.openedition.org/artelogie/344

DOl: 10.4000/artelogie.344

ISSN: 2115-6395

Editor

Association ESCAL

Referencia electrónica

Carlos Fajardo, « Colombia y su interminable paternalismo feudal », Artelogie [En línea], 9 | 2016,

Publicado el 20 junio 2016, consultado el 17 noviembre 2020. URL : http://journals.openedition.org/ artelogie/344; DOI : https://doi.org/10.4000/artelogie.344

Este documento fue generado automáticamente el 17 noviembre 2020

Association ESCAL 


\title{
Colombia y su interminable paternalismo feudal
}

\author{
Carlos Fajardo
}

El espíritu colombiano no ha logrado superar el paternalismo feudal Jorge Gaitán Durán

\section{¿Un país de cafres?}

1 «Este es un país de cafres», dijo el liberal Darío Echandía Olaya hacia 1979 ante la fogata histórica de una Colombia demente y desenfrenada en no terminar nunca su carrera de violencia. Es decir, un país bárbaro, cruel, rústico, safio, tosco, primario, incivil. Años después Echandía- en una entrevista concedida a Margarita Vidal se disculpó, no con los colombianos sino con los cafres, pues, dijo, «últimamente lo que me parece es que calumnié a los cafres». (VIDAl, 1979)

Bastantes décadas han pasado desde que dicha frase, casi diatriba, se estampara en nuestra pobre grandeza. Son años en los cuales más que mejorar la condición éticomoral de nuestra cultura ésta ha empeorado debido a la globalización de un neoliberalismo depredador, impuesto con perversidad universal. En el país, entonces, se han agudizado las tragedias éticas y fragmentado cada vez más los proyectos comunitarios.

3 Así, más de cien años de conflictos armados internos, de guerras atroces y desangres rutinarios nos han convertido en gente individualista, hostil, conservadora, tramposa, servil, envidiosa, oportunista, truhan, mentirosa, vivaracha, necrofílica, fundamentalista moral, a veces malandrines, otras exageradamente caritativas y amistosas. Tantas décadas destrozándonos entre nosotros y quedamos huérfanos de nosotros mismos. Esta es la sensibilidad del colombiano que ha atravesado el siglo XX y vive hoy por hoy en el XXI; es nuestra visión de vida, nuestra condición de época. Todo ello desemboca en una tradición trágica de la historia que legitima al sicariato mental y hasta real-, al sicariato simbólico que se gerencia en todos los estrados, bajo cualquier 
circunstancia. Matar, real o simbólicamente, al semejante que se oponga a nuestros deseos es un hecho aceptado, una garantía de triunfo personal. La envidia y el resquemor pululan en la cotidianidad enferma, grave, casi terminal; son los resultados de no haber conocido el verdadero sentido de una sociedad democrática, de haber escuchado meras mentiras sobre ella y de contentarnos con su falacia y simulacro.

4 A Colombia le fue negada durante toda su historia, por las clases no dirigentes sino dominantes, dicha democracia. Han sido años duros, precarios, cuyo resultado es en este caso una enfermedad mental de cultura. Ignorantes de un verdadero proyecto moderno, solo transmitido - y a veces - a cuenta gotas por muy escasos gobernantes; ingenuos frente a los discursos neoconservadores y neoliberales de última hora; sumidos en la idiocia de adoctrinamientos exquisitos; propensos a aceptar nuestra tragedia como un destino cruel e inevitable; huérfanos de espacios para la realización ciudadana, los colombianos sobrevivimos entre la dicha y el azote, la alegría de una fugaz victoria nacional y las matanzas rutinarias. Así es nuestra vida, así también nuestras múltiples muertes. ¡Ah país, la sangre que derramas, la pasión que no mereces!

\section{En el país del diablo}

5 En 1928, en su libro Viaje a pie, Fernando González, el filósofo de Otraparte, escribió lo siguiente sobre la mentalidad de los colombianos: «No tenemos ideas; no tenemos sino opiniones; de vez en cuando hacemos un soneto a Cristo Rey y por ello nos envían como diputados» (GONZÁLEZ,1976: P. 77). Páginas más adelante su pluma se torna más incisiva: «iPobre país, país de miseria, país del diablo, país negroide, indio, español, sin rumbo y sin consciencia aún! ¡Pobre país en que son condóminos EL CURA, EL BACHILLER Y EL DIABLO!» (GONZÁLEZ,1976: P. 146).

6 La ironía es patética; el sarcasmo mordaz. Y es que la Colombia de principios del siglo XX no podía ser más tradicionalista, conservadora y provincial frente a las nuevas corrientes de pensamientos liberadores y libertarios como los que se establecían en otros territorios. "Colombia, escribía González, está marchita como planta en verano porque no hay partidos políticos y únicamente hay ladrones que gobiernan sin concepto de patria, que es el de solidaridad con los que conviven bajo el mismo cielo» (GONZÁLEZ, 1976: p.194). Este filósofo "aficionado», como gustaba llamarse, sabía que «cuando nuestros conciudadanos se ponen a pensar, producen un sonido de cerrojo oxidado» (1976: p.231), y que «la gran tristeza es nuestra Colombia de hoy, que ya no tiene energías siquiera para producir revolucionarios» (1976: p. 238). «El clero ha pastoreado estos almácigos de zambos y patizambos y ha creado cuerpos horribles, hipócritas» (1976: p.16).

7 Leer a Fernando González constituye un encuentro emocionante que nos muestra la ironía como arma sagaz y certera, sin asomo de «retórica jesuítica», aplicada a desenmascarar una Colombia que le temía al desnudo, al placer corporal y a las alegrías de los cuerpos llenos de «ánima interior». Sin temor al pecado y al goce carnal, Fernando canta y alaba los sentidos terrestres palpitantes. Así, el sexo toma fuerza y forma en su obra como respuesta a la caridad de confesionario de su época, ante el puritanismo regeneracionista de los curas jesuitas:

Colombia, escribe, es el país del Diablo. Porque aquí se cree más en él y se le teme y ejerce oficio trascendental. Es el rey de los Andes. Colombia de hoy es un clan resucitado. Por todas partes, en los pueblos tristes, en los caminos retorcidos, en las 
selvas y en los puentes se percibe a este ser omnipotente. ¿Podrían existir el cura y el partido conservador si el Diablo no estuviera aquí, si no fuera con ellos condómino del país ?(1976: p. 145) llamada República Conservadora, el modelo de intelectual lo representaban el poeta, el gramático y el abogado, cuya finalidad era legitimar el régimen nacional vigente, limitando su producción a un esquema demasiado partidista. Desde 1886 esta situación se impulsó en el proyecto político y cultural llamado La Regeneración, que llegó a conformar una hegemonía conservadora hasta 1930. Los intelectuales y hombres de letras pusieron su pluma al servicio de las luchas ideológicas y partidistas, fundamentalmente oficiales. Esto da una idea de la estrecha relación entre el poder y la escritura como búsqueda de prestigio social, de puestos en la escena pública y política del país.

Como consecuencia, la llamada Regeneración de finales del XIX se constituyó en un paradigma de conservación de los preceptos de la iglesia católica y de la educación conservadora, doctrinas e ideologías impuestas de forma totalitaria ${ }^{2}$. Las instituciones asumían el orden y la defensa de la moral propuesta desde Roma por los papas Pío IX y León XIII. Así que el dominio de la iglesia se registró en todos los campos de la cotidianidad, de la cultura y la política, manteniendo su poder en los estamentos gubernamentales y educativos. A la vez, se condenaba y expulsaba todo pensamiento de índole liberal y socialista, toda vanguardia estética que se hiciera presente en el país. Para ello, la Iglesia y el Estado conservador se propusieron controlar la edición de los textos escolares y filosóficos, la organización del pensum académico y la educación moralizante de los docentes. Así, la represión de las ideas foráneas por la Iglesia fue el diario vivir en los ámbitos de la cultura colombiana.

En el campo del arte y la cultura, la hegemonía conservadora estableció que todo artista debería dedicarse a exaltar los valores de la herencia española, la moral católica y a conservar las tradiciones de raza, religión e idioma ${ }^{3}$. Todo este programa estatal se oponía a las nuevas tendencias culturales y artísticas liberales y de vanguardia. De esta gama ideológica conservadora surgió el paradigma del intelectual gramático católico, entre cuyos principales representantes se cuentan los ex presidentes Rafael Núñez, José Manuel Marroquín, Miguel Antonio Caro (quien participó, junto a Núñez, en la redacción de la Constitución de 1886), el gramático Rufino José Cuervo, intelectuales que instauraron la utopía de volver a Colombia una República Heleno-católica - ya propuesta años atrás por José Eusebio Caro y Sergio Arboleda -, cuyo centro intelectual fuera Bogotá, considerada la «Atenas suramericana». Ansiosos por llevar a cabo su objetivo, se enfrentaron al discurso liberal radical, proceso que culminó en la guerra de los Mil Días (1899-1902), cuando los liberales se opusieron al férreo totalitarismo conservador del presidente Sanclemente y del vicepresidente Marroquín. Sin embargo, a pesar de la oposición, la anhelada «Arcadia» colombiana, heleno-católica, se fue imponiendo como modelo cultural, social y político.

11 La hegemonía conservadora institucionalizó también algunos mecanismos de control y vigilancia de las ideas de avanzada. Así, se impuso «la Ley de prensa que estableció la censura, la inspección eclesiástica de los periódicos liberales, los reglamentos de los 
colegios, el Index, el control sobre los textos escolares, etcétera» (URREGO, 2002: 43). En esas condiciones, Colombia se cerró a todo pensamiento foráneo innovador y se centró en un provincianismo radical que repercutió en la formación de sus intelectuales y de sus poetas. Este cierre de fronteras evidenció el atraso cultural del país frente a otros países latinoamericanos, como Chile, Argentina y México, que procedieron a abrir sus fronteras a nuevos aires culturales e ideológicos. En Colombia, dicho encierro «en el campo literario y artístico, el rechazo se expresó en la persecución a los más importantes miembros de algunas escuelas literarias, especialmente los románticos y los vanguardistas, que no solamente trastocaban las formas establecidas de usar el lenguaje sino que abordaban temas que a la luz de algunos amigos de la censura resultaban inaceptables y de ninguna manera adecuados para un buen católico» (URREGO, 2002: 44).

El miedo a las corrientes vanguardistas europeas y latinoamericanas, y el apego a la ideología hispanista, se manifiesta en la gran mayoría de intelectuales colombianos que asumieron la literatura española como modelo a seguir y paradigma estético político. La sumisión al hispanismo y a la iglesia, configuró a un intelectual nada autónomo frente a las ideologías dominantes, a un intelectual conciliador y colaborador con el establecimiento, de ninguna manera nada independiente en sus idearios políticos y estéticos. Al no tener autonomía crítica, la modernidad para el intelectual colombiano estaba todavía por construirse.

La crítica literaria y estética de estos años se preocupó por mantener el control ideológico, más que por realizar un análisis riguroso y serio de las obras. Era una crítica pastoril, tradicional, cerrada y jerárquica que legitimaba a escritores oficialistas. Distanciarse de la iglesia, de la moral y del conservatismo significaba impulsar la crisis de la nación y del Estado, la disolución de la verdad, y entrar a la caótica situación del libertino. Con estos argumentos se asumió que la libertad estética era pecado y el artista e intelectual vanguardista un culpable por ser corruptor de las costumbres y sensibilidades. Así, la idea del artista bohemio, sensualista, libertario, socialista, de vanguardia, fue considerada causa de expulsión del país y de excomunión.

De modo que los escritores aceptados por la institución eran los seguidores de los dos Caros (de José Eusebio y Miguel Antonio), de Rafael Núñez, de Rufino José Cuervo, entre los que se contaban el poeta erudito Rafael Pombo, la novelista conservadora y moralizante Soledad Acosta de Samper, el caucano oligarca Eustaquio Palacios -autor de El alférez real-, los conservadores José Manuel Marroquín y Marco Fidel Suárez. A su vez, la ideología de la república conservadora puso en la picota pública y en tela de juicio las obras de escritores contradictores como José Asunción Silva, José María Vargas Vila, Luis Carlos el Tuerto López y Tomás Carrasquilla, nada cercanos a las ideas de la Regeneración. El Tuerto López introduce en la poesía colombiana la ironía, el sarcasmo y la parodia crítica al ambiente pueblerino de su Cartagena natal. En el caso de José María Vargas Vila, sus obras fueron ubicadas en el Index o lista de libros prohibidos por la iglesia católica, por el tratamiento del tema erótico y de prácticas sexuales escandalosas. Aura o las violetas (1889), Flor de fango (1895), Ibis (1900), entre otras obras, expresan una ideología libertaria y maldita en medio de una cultura tradicional y retrógrada.

15 Negados a la libertad de expresión y de creación, a los artistas y poetas les quedaba, o bien fusionarse con la ideología hispano-católica conservadora o bien vivir a la intemperie, al margen, fomentando desde otras orillas un espíritu crítico, abierto a los 
aires de una estética renovadora. Esto último ocurrió en algunos escasos libertarios, solitarios y autónomos, marginados, en guerra abierta contra la tradición retardataria e inquisitorial.

16 En consecuencia, en la Regeneración se impulsó el centralismo político y cultural, legitimando a Bogotá como la Atenas Suramericana y al "cachaco" bogotano como el modelo nacional ${ }^{4}$. Este centralismo excluyente impuesto por una aristocracia bogotana se desarrollará hasta bien entrado el siglo XX, promoviendo la diferencia entre el intelectual "culto" del altiplano andino con el "inculto" de las provincias de tierra caliente, de raza inferior y "salvaje". Civilización frente a barbarie. La imagen del "cachaco", conservador, católico y moralista va a promoverse en Colombia como única posibilidad de acceder a la cultura oficial en contra de lo popular. Esto, más que contribuir a la fundación de imaginarios de unidad nacional, genera procesos de fragmentación. Provincia versus centralismo; intelectualidad bogotana versus incultos provincianos. Tal es el imaginario que prosperó a lo largo del siglo XX.

17 Guardianes de la tradición, los intelectuales y artistas del periodo conservador se esforzaron por mantener las ideas del modelo estatal nacionalista, centralista, el orden institucional, la moral cristiana y los cánones del pasado ${ }^{5}$. Su misión era moralizar al país y de educar en las "sanas costumbres. La literatura se presentaba como un proyecto pedagógico doctrinal, más que como propuesta crítica que reivindica a la duda, la sospecha y la ruptura con las realidades existentes. Un ejemplo de esto se halla en las revistas de la época, las cuales -faltas de crítica moderna y de autonomía de pensamiento - se presentan como beneficiarias de un régimen cerrado, provincial y premoderno ${ }^{6}$.

18 Pero si este era el país del cual se burlaba Fernando González, la pintora Emma Reyes, en sus cartas a Germán Arciniegas, escritas entre 1969 y 1997, narra los horrores ideológicos, políticos y religiosos en la Colombia de la década del treinta. En dichas cartas retrata los resultados desastrosos de la Regeneración y de la República Conservadora, retardataria, clerical y patriarcal. Sus palabras son el testimonio más vivo y atroz de nuestra demencia cultural, del atraso no solo económico sino moral, del despotismo y dogmatismo de una doctrina religiosa en contra de la libertad individual y colectiva civil.

19 Emma Reyes es víctima de un país conventual, terrateniente, gamonal, ajeno a las voces externas de la modernidad y de las vanguardias político-culturales, educativas. Las narraciones de su paso por el convento son escabrosas y conmovedoras. Producen asombro, rabia y tristeza. Las monjas son retratadas como tiranas, explotadoras de niñas huérfanas y abandonadas, doctrinadas, con disciplina férrea, a través del miedo y del terror. Las religiosas, serviles de la ideología conservadora y simuladoras de caridad cristiana, provocan paranoia y maldad para justificar los castigos. Tal es el retrato del país de los años treinta, de aquel que le temía al diablo, como lo bautizó nuestro Fernando González. Escuchemos a Emma Reyes:

Nuestras vidas estaban designadas a dos únicos fines que marchaban al mismo tiempo: trabajar al máximo para ganar lo que nos comíamos y, según las monjas, salvar nuestras almas, protegiéndonos de los pecados del mundo, pero el precio que pagábamos por salvar nuestras almas representaba para nosotras diez horas de trabajo por día (REYES, 2013: p. 111).

En otro apartado comenta:

Nuestro único enemigo era el Diablo. Del Diablo sabíamos todo, sabíamos más del Diablo que de Dios. Conocíamos todos sus trucos, todos los medios de los cuales se 
servía para hacernos caer en el pecado. El infierno también lo conocíamos hasta su último rincón. Teníamos la impresión que podíamos recorrerlo con los ojos cerrados, conocíamos cómo eran las pailas de aceite hirviendo donde el Diablo metía a los pecadores desnudos y luego los sacaba y les quitaba la piel a pedacitos (...). El Diablo era grande, muy ágil, podía dar saltos de varios metros, estaba siempre vestido de rojo o de un verde fosforescente, su pelo estaba siempre de punta hacia arriba y tenía además cuernos como los toros, sus ojos eran amarillos y lanzaban llamas. Si uno había pecado con los ojos, el Diablo le sacaba a uno los ojos con unas agujas calientes y, si había pecado con la boca, él le cortaba la lengua a uno a pedacitos. Nada ignorábamos del Diablo, además no nos lo dejaban olvidar (...) (REYES, 2013: p. 114).

Tal vez no hayamos superado en este siglo XXI al país monacal y conventual retratado por Emma Reyes. Quizás seguimos y seguiremos definiendo nuestra cultura con bases religiosas, mezcladas eso si con procesos racionalistas instrumentales del capitalismo neoliberal ecónomo, y con estructuras tecno-mediáticas tiránicas. Aún nos mantenemos como cultura mentalmente sumergida en el convento que describe Emma, llenos de paranoias e idiotizados por mitos de una pre-modernidad vigente, permanente y de reclusión. Emma Reyes al describir su vida en el convento nos relata:

No teníamos derecho a pedir explicaciones de nada, lo del mundo era pecado y punto; por eso en nuestras oraciones, tanto a la hora de empezar a trabajar como a la noche, siempre decíamos unas cuantas Aves Marías por nuestros clientes pecadores que nos beneficiaban con sus trabajos para que nosotras pudiéramos comer y salvar nuestras almas (...) Por esa razón nunca se nos ocurrió ni protestar, ni reclamar justicia. Nuestras vidas no tenían porvenir y nuestra sola ambición era la de pasar del convento derecho al Cielo sin tocar el mundo" (p 113). (...) Las monjas hablaban del pecado, el Diablo, el Cielo, el Infierno, salvar nuestras almas, ganar indulgencias, arrepentirnos de nuestros pecados (...) Nosotras teníamos miedo que nos abandonaran por estar en pecado (REYES, 2013: págs. 102-103).

21 Llenas de miedo y de terribles castigos, las niñas en el convento se resignan, se persignan y se les culpabiliza por su condición. Es el horror de los horrores leer estas páginas maravillosas y crueles de una colombiana internada en el verdadero infierno secular de nuestra cultura monacal. Así fue la educación que recibimos durante años, a la cual debemos la pobreza cultural que padecemos. Bajo estas condiciones se levantó el país y aún sigue sobre estos cimientos. Un gran porcentaje de la miseria moral que padecemos se la debemos a la educación religiosa que recibimos durante más de un siglo, y a la institución clerical, pues nos alejó de la modernidad encerrándonos en un país provincial, creyente y paranoico, nada crítico e inquisidor, dogmático y resignado, violento por adoctrinamiento, esclavo por aturdimiento.

\section{Una perpetua regeneración}

La Regeneración, escribía Vargas Vila a sus 26 años, no puede existir ante la libertad de la prensa porque ¿cómo defender su origen, su constitución, sus leyes, sus cadalsos, sus robos, sus saqueos, todo ese arsenal de delitos, y sofismas que llama sus principios? Imposible (VARGAS VILA, 1998: p.193).

Tal es el mapa de finales del siglo XIX, tal el mapa de esta segunda década del siglo XXI.

El dogma, el destierro de todo debate de ideas, la invisibilidad de los intelectuales a contracorriente, los predicadores políticos de aldea, la retórica bárbara de los medios y de los periodistas analfabetas, la negación al contradictor desde la academia, es nuestro sino contemporáneo. De allí que, prosigue Vargas Vila, "cuando en un país la libertad 
ha muerto, no queda ya una Nación, sino una ruina. - Hoy, Colombia es una tumba, sobre la cual ondea la bandera ensangrentada de los conservadores, agitada por todos los vendavales, desde el huracán de la ambición, hasta el huracán de la miseria" (VARGAS VILA, 1998: p. 197).

Hoy también el país sigue siendo una tumba, donde se impone el silencio en el cual se escuchan solo unas cuantas voces exigiendo romper el mutismo, mientras la mayoría de los ciudadanos calla, acepta, o se resigna.

En Pretéritas, primer libro político, "principiado en la guerra, concluido en la derrota y publicado en el destierro", como lo escribió el autor en el prefacio, Vargas Vila ya había vislumbrado el futuro de una Colombia víctima de hombres mediocres y ruines, y presentido los años que le esperaban la patria en medio de los azotes de su historia partidista y sectaria. Lo había escrito en su Diario Íntimo en 23 de Julio de 1910: Consumí mi juventud, combatiendo hombres y partidos que no valían la pena de mi esfuerzo, y muchos de ellos, no vivirán en la historia, sino por el traje que yo les hice" (VARGAS VILA, 2000: p.54).

En medio de su destierro de un exilio perpetuo tanto espiritual como político, Vargas Vila escribió desde París, en junio de 1900: “mi corazón está poseído por el Amor a la Libertad; no ha conocido otro; él ha devorado mi Vida, y no ha permitido que ningún otro nazca, al lado suyo, para hacerle competencia (...) La libertad fue mi culto y mi lema" (VARGAS VILA, 2000: págs. 45 y 59).

Ese fue "el Divino" Vargas Vila, asediado, desterrado, amado, odiado, admirado por tantos y repudiado por muchos en un país que lo vio como ángel ácido y demonio; el que nació en "plena guerra, en una ciudad absolutamente bárbara en asuntos de arte" como bien la definió; quien en la última página de su Diario en 1932, año de su muerte, escribió: "Hay seres que nacen fuera de toda sociedad; yo he sido uno de esos..." (VARGAS VILA, 2000: P.215).

Férreo opositor de la Regeneración, y especialmente de Rafael Núñez de quien dijo que "tenía la densa oscuridad del abismo", Vargas Vila arremetió con su pluma contra todo dogmatismo y mediocridad ética y política conservadora e hispano-católica, pues, en sus palabras, la Regeneración no es un principio sino la negación de todos los principios (...) Es la orgía del despotismo. En uno de esos momentos de seria ferocidad nos arrojó al rostro su Constitución de 1886, (la cual) vista de lejos tiene el aspecto de un castillo feudal en la sombra (...) De lejos inspira horror, de cerca risa (...) Aparición del siglo XVII en pleno siglo XIX, es un fenómeno" (VARGAS VILA, 1998: págs.124-125).

Las coincidencias con las condiciones histórico-políticas de principios del siglo XXI son grandes; las situaciones muy similares, mas, cuando el caudillismo presidencialista colombiano produce un tipo de gobernante retrógrado, dictatorial, doctrinario católico que, similar a Rafael Núñez, es "la personificación terrible de la venganza", de la maquinación, o como lo escribe Vargas Vila, "hay tiranos de batalla y tiranos de sacristía. Tiberio era un tirano soldado, Núñez es un tirano jesuita" (1998: p.123). La Regeneración produjo estos despotismos demagógicos, oligarcas y racistas. Excluyó de toda posibilidad democrática al pueblo analfabeta, pobre, hambriento. La Regeneración y su constitución, que concentró el poder en un centralismo capitalino y en el clero fanático doctrinario, "no habla de derechos, porque no los reconoce. Pero habla de deberes, porque los impone" (VARGAS VILA, 1998: p.126). 
29 Más aún creó “criminales sin responsabilidad, una monarquía disfrazada, la imprenta muda, nada de instrucción, nada de trabajo, nada de luz, retrocediendo casi a un estado primitivo" (VARGAS VILA, 1998: p.128). Es decir, al oscurantismo histórico que ha envuelto durante casi siglo y medio a Colombia. Tal es la radiografía de finales del siglo XIX: censuras, hogueras, cadalsos, fanatismos, conventos, asesinatos, sombres y más sombras, una "República tísica rodeada de bayonetas", levantada con un pie en el ejército y otro en el clero, con la prensa y la opinión manipuladas, con "un tirano sin grandeza, déspota sin gloria", que llamó a los Yankees en su ayuda y permitió que invadieran el territorio y acribillaran a balazos las tropas colombianas en Panamá; que hizo "retroceder al país un siglo", que cerró las escuelas y abrió los conventos. Este fue, y todavía lo es, el país que retrató Vargas Vila hacia finales del XIX y principios del siglo $\mathrm{XX}$, sobre las ruinas que dejaba la Regeneración ${ }^{7}$..

\section{Nuestro paternalismo feudal}

La revolución invisible, ensayo del poeta Jorge Gaitán Durán, escrito en diferentes entregas entre mayo y diciembre de 1958, "era en última instancia, como lo afirma el poeta, la búsqueda de un apolítica", en medio del Pacto Partidista que daría como resultado el llamado Frente Nacional entre 1958 y 1974. Para Gaitán Durán su ensayo invitaba a salir del feudalismo colombiano hacia una modernidad capitalista democrática. Tal fue su ejercicio de reflexión, su propuesta de renovación políticocultural. Industrialización y reforma agraria, según Gaitán Durán, eran dos formas de superar la "Edad Media Ladina" y la trágica violencia que ha sostenido la sociedad colombiana durante casi toda su historia republicana.

Nos interesan estas reflexiones, sobre todo porque introducen una aguja sobre la llaga de la cultura patriarcal, moralista, semi-feudal que en los años cincuenta se sostenía en los andamios jerárquicos y hegemónicos conservadores, los cuales todavía hoy son las piedras fundacionales de nuestra tradición política y social. Y nos interesan porque, como intelectual y poeta, Gaitán Durán sostuvo hasta el final de sus días la petición de levantar las creaciones estéticos-poéticas con bases en actitudes éticas, manifiestas en el compromiso por los otros, con la libertad, la crítica, la rebeldía y el inconformismo con lo establecido.

Esta correspondencia entre la obra artística y la vida del creador, nada indiferente a los sucesos de su tiempo, fue lo que impulsó el poeta a realizar una radiografía del país - y de su época - con una determinación independiente frente a los dogmatismos y fanatismos políticos y religiosos. Puso, como lo enunció en el primer número de la Revista Mito, sus palabras en situación. Precisamente la aventura intelectual de dicha revista sintetizó esas apuestas. Bajo la amenaza de la censura de prensa, consagrada en la Constitución Política desde 1886; frente al poder de la censura ejercida tanto por el gobierno como por la curia; entorno a las críticas a terratenientes e industriales como a la oligarquía retardataria y a una izquierda sectaria, Mito - y su fundador prosiguieron en la tarea intelectual de llevar a cabo "la realización de la Reforma Ética del País, cuya estructura moral y cuyos estilos de conducta han sido implacablemente socavados", como se lee en el editorial de la revista de octubre y noviembre de 1957.

Con una actitud independiente y crítica, en la cual, según sus propias palabras, existe una profunda unidad entre la labor crítica y la labor poética, donde reflexión y arrebato van juntas, el ensayo La Revolución Invisible analiza la situación colombiana bajo las 
hegemonías culturales provenientes de la Regeneración Conservadora del finales del siglo XIX. En el capítulo titulado "El Presidente y los Burgueses", Gaitán Durán, en dura confrontación con las formas autoritarias imperantes escribe:

No puedo admitir que Colombia sea desfigurada por un clericalismo energúmeno, rechazado por católicos tan eminentes y tan representativos del moderno pensamiento cristiano como Mauriac o La Pira y, más cerca de nosotros por Rafael Caldera. No es posible que, mientras el país se desarrolla y supera sus abrumadoras limitaciones estructurales, vayamos a ser modelados espiritualmente por la censura, la intolerancia y el fanatismo. Para mí, la libertad, aún en sus formas más extremas, no es una farsa o un recurso demagógico, sino una necesidad humana que hay que defender cotidianamente (GAITÁN DURÁN, 1999: págs. 24-25).

Escrito en el año 1959 suena muy actual y, por lo tanto, demasiado preocupante. Junto a ello, el poeta observa cómo la burguesía - en especial Alberto Lleras Camargo - posee una "adhesión irrestricta al modo de vida norteamericano", como si la radiografía de la década del 1950 fuera la misma de la segunda década del siglo XXI. Y agrega, "dentro de cinco años el país debería aspirar a estar relativamente independizado del comercio exterior, lo que quiere decir que no importaríamos sino las materias primas que físicamente no pudiéramos producir, que no importaríamos alimentos, que solo importaríamos las máquinas que no produjera el país, pues es mucha la que podría ser colombiana (...) mientras esto no se logre continuaremos siendo Menores de Edad en el conjunto de las naciones del globo" (GAITÁN DURÁN,1999: pág. 32).

Como una premonición a la inversa de lo que pasaría con los Tratados de Libre Comercio (TLC), Gaitán Durán retrató en negativo de lo que Colombia haría cincuenta años después dominada por un neoliberalismo depredador y perverso, embarcándose así en una dependencia económico-cultural donde "la mentira, el conformismo, el desprecio por el pensamiento han sido elevados al rango de instituciones nacionales" (GAITÁN DURÁN,1999: pág. 33). La petición del poeta de construir un gran proyecto nacional centrado en dos grandes transformaciones: la Reforma Agraria y la Industrialización del País, hoy por hoy ha quedado sin bases y sin posibilidades. Desindustrializado el país y casi con el agro a punto de desaparecer, los prospectos político-económicos de una burguesía moderna y dirigente se disuelven sin pena ni gloria, quedan en la campana del vacío. Hace cincuenta años, Gaitán Durán todavía veía posible construir una Colombia acorde a las concepciones de la modernidad ético política, tal como en otros países del hemisferio se gestaba. Utopía o posibilidad, lo cierto es que el poeta apuntó con certeza a los blancos más sensibles de un país casi feudal, lleno de fanatismos religiosos, militares y partidistas. En medio de estos fundamentalismos ¿cómo lograr realizar el proyecto civil de una modernidad educativa, ético política?

Esta "feudalidad, hermética y reconcentrada", al decir de Gaitán Durán, ha producido una violencia a gran escala durante casi toda nuestra historia. Sin embargo, hay que "preguntarse qué terreno de predisposición lleva al hombre colombiano a recurrir colectivamente al asesinato, al robo, a lo ilícito y lo monstruoso, en su búsqueda de poder y de riqueza; hay que preguntarse por qué la violencia se instala con tanta facilidad y por tan largo período en el carácter social del colombiano (...) rozamos así una dimensión abismal: las causas sociológicas y psicológicas de nuestra tragedia" (GAITÁN DURÁN, 1999: pág. 44).

Tanto las causas políticas, económicas y psicológicas de la violencia muestran el fracaso histórico de los proyectos colombianos. Son un mapa de frustraciones generacionales, 
“indican, como lo argumenta el poeta, que el hombre colombiano está reprimido, insatisfecho, angustiado, que no tiene posibilidades normales de amor, cultura, prosperidad y poder, y en consecuencia no consigue impedir que en él se desarrollen imperialmente, al menor estímulo exterior, las tendencias destructoras (...) más que en otra patria cualquiera en nuestro país el hombre ha sido una 'pasión inútil"' (GAITÁN DURÁN, 1999: pág. 45).

Sin partidos políticos modernos, con estructuras conservadoras, con un país semifeudal, clerical, militar, presidencialista, "la educación colombiana - en la escuela primaria, el bachillerato y la universidad - siguió siendo, durante los dieciséis años del gobierno liberal, retórica y clerical, correspondía a nuestra Edad Media, estaba en retardo sobre la historia" (GAITÁN DURÁN, 1999: pág. 60).

Esa es nuestra "burocracia feudal", nuestro destino de país solo consumista, depósito o reserva de materias primas para los imperios. De esta manera, como en los tiempos de Gaitán Durán, "los malos humores invaden por todas partes la vida colombiana", pues, "el espíritu colombiano no ha logrado superar el paternalismo feudal" (GAITÁN DURÁN, 1999: págs. 138-142).

Hasta esta segunda década del siglo XXI nuestros procuradores, periodistas, fiscales, algunos intelectuales, profesores y burócratas, siguen legitimando al país del Índex y prohibiendo discursos de la diferencia como hace más de cien años.

\section{La ideología de la mediocridad}

41 En 1987 el escritor colombiano R.H. Moreno-Durán publicó en el "Magazín Dominical" del Diario El Espectador el contundente y crítico ensayo "por una escritura disidente". En él reflexionaba sobre las condiciones culturales del país hacia esos años. Pocas cosas han cambiado desde entonces. Todavía este país "parlanchín y legalista", según lo denomina Moreno-Durán, "niega con el metódico cultivo de sus excesos una definición de lo que considera sus máximas virtudes (...). Por ello, en un país oscuro y charlatán, embriagado por el monocorde ritmo de su fantasía verbal, una voz propia suena a disidencia. (MORENO-DURÁN, 1987: p. 14).

Es el país de las rencillas parroquiales, de pactos de amistad y de sangre, proveniente de una cultura nada moderna, más bien mafiosa y provincial; un país que piensa la cultura - y a los creadores de la misma - con una noción de núcleo familiar de capilla, y que ejerce la exclusión al diferente, al que no pertenece al clan, al mismo tipo de sangre, a la misma cofradía. Pensado y construido con unos imaginarios retardatarios, la meritocracia es destrozada por una burocracia mediocre y utilitarista jerárquica, de "microempresa familiar" en términos de Moreno-Durán. El país de nuestra imagen se muestra entonces nuclear, vertical, autoritario, aldeano, retrógrado, que exilia al diferente.

"Las tareas del clan, dice Moreno-Durán, le dan rango antropológico a las compulsiones de un país temeroso de lo que resulta extraño, incomprensible o incómodo" (MORENODURÁN, 1987: p. 15).

Basta sólo ver las actitudes de los grandes medios para dar cuenta de dichos propósitos. Es como si el odio y la repulsión hacia el que piensa en contravía fuera el propósito último de la función cívica y pública. La estrategia es efectiva: se siente y se vive que todo el país, toda la cultura, junto al Estado, son enemigos del ciudadano, pues este es el 
culpable de las desgracias nacionales y, por lo tanto, debe purgar su culpa. Se nos condena a todos por lo que han cometido unos pocos. La máquina de culpabilidad opera y triunfa. Es una guerra interiorizada que se filtra en la mayoría de nuestras maneras de ser y de actuar en el día a día. Concebida la existencia de esta manera, sólo queda la esquizofrenia en red, la frustración total, la imposibilidad ante los límites de un país enemigo de todos y que alimenta la sensación del fracaso.

Así, favoreciendo unos intereses pseudo-feudales y desterrando otros al olvido, se ha instaurado entonces la llamada por Moreno-Durán "mediocridad como ideología", (1987: P. 15) lo cual sentencia al opositor a un ostracismo físico o simbólico y a su muerte como pensador y ciudadano. Más aún, procede a realizar, con una actitud mordaz, perversa, la misión de hacer sentir extranjero, sátrapa, bastardo, hijo de otra raza, al diferente. Xenofobia cultural, exclusión permanente.

Con estas proyecciones históricas se oscurece el panorama, nuestro futuro. "Una de las características del colombiano es su obsesión monotemática, su discurso rutinario, su patético soliloquio, algo que en realidad constituye la versión cultural del monocultivo" (MORENO-DURÁN, 1987: p. 17).

Las frases incisivas de Moreno-Durán dan cuenta de nuestra situación de atraso, del estatismo y del encierro ante las propuestas políticas y culturales renovadoras latinoamericanas y mundiales, siendo esto nuestro sino histórico.

\section{El macondo encantado}

Esta misma concepción la sostiene Fernando Cruz Kronfly en su ensayo "Macondo: la aldea encantada"; aldea a la cual no ha llegado el "desencantamiento del mundo" efectuado por la modernidad.

Si la aldea donde suceden los hechos y las historias de Cien Años de Soledad se encuentra aún encantada, esto significa que allí no ha ocurrido la secularización de la cultura y que sus personajes y los acontecimientos ligados a ellos se deben entender inscritos en una etapa de la historia de la humanidad anclada, en razón de sus mitos y premoniciones, en la pre-modernidad mental y cultural (CRUZ KRONFLY, 2016: págs. 215-216).

De manera que este mundo no moderno es el que les ha correspondido en suerte a los habitantes de Macondo. Metáfora de un país que se encerró a los procesos de la racionalidad secular, conociendo el aislamiento respecto a las concepciones ético-laicas de la modernidad. En cambio, se impuso el dominio de una ideología hispano-católica conservadora, con gran fuerza en el pensamiento mítico-mágico religioso. Para Cruz Kronfly ese es el nudo de nuestro anacronismo y desajuste histórico: "Los avances de la ciencia y de la técnica son vistos en la aldea encantada desde un mundo simbólico premoderno, desde un sistema mental encantado que se asombra y que atrapa y reinscribe lo nuevo en lo mítico-mágico-agorero tradicional" (CRUZ KRONFLY, 2016: P. 224).

El aislamiento y el anacronismo han moldado entonces nuestra sensibilidad cultural e histórica, y donde las ideas de inutilidad y de fracaso son las que plenamente triunfan. "En la aldea encantada, escribe Cruz Kronfly, los mejores emprendimientos terminan en el fracaso, en lo contrario de lo previsto, casi siempre con efectos al revés de lo que se esperaba. El tiempo se muerde la cola, es cíclico y no se parece en nada al tiempo lineal que domina el mundo moderno" (2016: P. 231).

Un mundo circular, cerrado, vertical. Nunca horizontal, expansivo, liberador, libertario. Se vive en una no modernidad que en nuestra cultura se reactualiza y se hace 
vigente y utilizable, como también en una modernidad a medias y una globalización tecno-cultural mercantil. Por consiguiente los colombianos hemos quedado atrapados en una especie de sonambulismo histórico, fluctuando de un imaginario a otro. Para Cruz Kronfly esa es nuestra chifladura, nuestro despiste cultural.

\section{Una cultura de siervos y señores}

51 Muchos años de escasa o casi nula democracia, han preparado al colombiano para que posea una mentalidad de súbdito, siervo de la gleba, servil de los grandes poderes y señores del latifundio nacional. Estos patrones educativos gestaron un proceso de domesticación cultural durante décadas, desterrando la autonomía e independencia del colombiano en relación con las estructuras hegemónicas tradicionales. La proliferación mediática, junto a una educación doméstica, han retroalimentado los imaginarios de servidumbre, resignación, silencio y dependencia, promoviendo una mentalidad de obediencia y de seres sin proyecto nacional.

Entre una religión hispano-católica, dogmática, excluyente; unas clases conservadoras tradicionales, una burguesía industrial y financiera retardataria y antipopular, se ha movido la historia del país. El asunto se vuelve más horrendo cuando a la mentalidad de servidumbre se le acepta como algo natural, normal. Comisarios y agentes legitimadores de los regímenes defensores de verdades totales nos lo hacen sentir así, produciendo estos imaginarios muy rentables y terribles resultados. Bajo este ambiente, el desvío de la norma se constituyó siempre en un desafío, un peligro supremo. Décadas de sistemas represivos nos han acostumbrado a ubicar en el cadalso al diferente. A veces se le condena sin pruebas, con furia, crueldad y placer. Al descarriado, desobediente, que asume su derecho a disentir, se le expone ante la picota pública o se le "invisibiliza" de diversas y puntuales maneras. Esa fue y es todavía la táctica de nuestras jerarquías. Ha sido un proceso de disciplinarización mental y corporal. Controlar, judicializar, infantilizar, criminalizar al otro y al opositor ideológico, son formas de represión que asimiló el colombiano, el cual vio, y ve lejana y hasta imposible - la rebeldía de una acción libertaria para ejercer su propio entendimiento.

53 Así las cosas, se diría que promover la resistencia y, aún más, la re-existencia, en nuestro país ha sido uno de los dramas históricos más traumáticos que hemos padecido. Por lo mismo, la sociedad colombiana ha aceptado la militarización policial como entidad salvadora. Los resultados son catastróficos: vigilancia y desconfianza entre unos y otros; dificultad para construir una ética del respeto y de la alteridad entre los ciudadanos; violencia simbólica, golpes reales. He aquí los imaginarios de nuestro Estado Nacional, impuestos como modelos de conducta colectiva.

De allí que bien lejos, y muy extraña, nos ha quedado la idea de una democracia participativa, pues a la gran mayoría se les expulsó de dichos procesos. Con desprecio por el pueblo, la clase dominante del país impidió tener unas condiciones económicas más justas y una educación ética moderna que superara la formación casi feudal hispano-católica nacional, es decir, puso trabas a un proyecto de nación más solidario e incluyente.

No fuimos educados para ser ciudadanos con ideas liberadoras, de alteridad y respeto a la diferencia. Al contrario, nos lanzaron al circo de la historia a devorarnos los unos a los otros, con antivalores de avaricia, odio, indiferencia, envidia, competencia 
individualista, obediencia servil, racismos, discriminación y destrucción al compatriota. De este modo, ¿qué se podrá esperar de una nación, terrible y bárbara, que nos deja náufragos y con una ignorancia antidemocrática e incivil suprema?

Ya Estanislao Zuleta en la conferencia leída el viernes 21 de noviembre de 1980 en el acto en que la Universidad del Valle le otorgó el Doctorado Honoris Causa en psicología, anunciaba que: "la pobreza y la impotencia de la imaginación nunca se manifiestan de una manera tan clara como cuando se trata de imaginar la felicidad. Entonces comenzamos a inventar paraísos, islas afortunadas, países de cucaña. Una vida sin riesgos, sin lucha, sin búsqueda de superación y sin muerte. Y, por tanto, también sin carencias y sin deseo: un océano de mermelada sagrada, una eternidad de aburrición. Metas afortunadamente inalcanzables, paraísos afortunadamente inexistentes". (ZULETA, 2016: P. 163). Texto incisivo, lúcido, irónico y peligroso para ciertos espíritus prisioneros del miedo, deseosos de respuestas y no de preguntas, introduce el dedo en la llaga en una cultura que más allá que desear construir el mundo, quiere recibirlo ya hecho.

De eso trata su ensayo "Elogio de la Dificultad": un golpe bajo a nuestra dependencia y al resentimiento; un alegato a la falta de fuerza de voluntad, de autonomía crítica para pensar por nosotros mismos, en el lugar del otro y de ser consecuentes; es decir, una visión desgarrada de nuestra flaqueza y minoría de edad a la hora de construir democracia real.

Zuleta lo sabe y nos lo recuerda: "Deseamos mal. En lugar de desear una relación humana inquietante, compleja y perdible, que estimule nuestra capacidad de luchar y nos obligue a cambiar, deseamos un idilio sin sombras y sin peligros, un nido de amor, y por lo tanto, en última instancia un retorno al huevo". (ZULETA, 2016: P. 163-164). Al unísono con otros escritores y pensadores seleccionados en este escrito, Zuleta pide tener una actitud analítica y contestataria que produzca rupturas en las estructuras del establecimiento, en los actos de fe y en los poderes tradicionales. Atreverse a pensar es iniciar el camino hacia la escisión que conduce a la duda y a la angustia, y esa es ya una postura soberana, valiente, lejos de solicitar libros y verdades totales, sagradas. De este modo, se superan los sectarismos y fundamentalismos últimos, los cuales suponen que el Otro es un enemigo cuando no comparte nuestros principios; síntoma de una de las enfermedades más crónicas que padece Colombia: aniquilamiento de toda diferencia.

La crítica a los espíritus sedentarios, que giran siempre en torno a certezas absolutas sin asumir la alteridad, no podría ser más mortífera en un país que ha impuesto barreras al pensamiento moderno y reflexivo.

\section{La colombia que inventamos}

Lo anterior ha hecho que desemboquemos en un espontaneísmo cultural siniestro y perverso. La improvisación nos consume, el "ahorismo" inmediatista nos asalta. He aquí dos concepciones vigentes entre nosotros: por una parte, la falta de una verdadera planeación racional, con una panorámica de los procesos institucionales, lo cual si existe, es solo a nivel formal; por otra, la posmoderna y líquida sentencia de que todo se hace para un "ahora", todo se constituye en un "para ya", lo que echa en saco roto la idea de organización proyectiva. Como consecuencia tenemos cierta neo-esclavitud constante, ejercida sobre el trabajador, pues éste debe dar cuenta de forma instantánea 
sobre tareas no planeadas e impuestas de manera inmediata. La planeación se hace, pero de forma instrumental, para el momento, para las necesidades del instante.

Esto retrata otro de nuestros rasgos: el despotismo administrativo. Hijos de una cultura autócrata y en guerra constante, nos hemos vuelto déspotas cotidianos. Al "otro", al semejante, sólo se le piensa o bien para neo-esclavizarlo, o bien para sacarle provecho. De allí que nuestra burocracia sea abundante, ineficiente, servil y humillativa frente a los "subordinados". Una burocracia sorda ante los reclamos del "otro", al cual por lo general se le trata con indiferencia, dureza y negligencia. La indiferencia es su signo, el despotismo su condición y, por supuesto, la improvisación sus resultados. Ineptitud e intransigencia; lentitud e ineficacia mental, déspotas, improvisadores atroces somos los colombianos.

Con todos estos ingredientes hemos asumido una actitud estoica y miedosa, dos formas de ser que alimentan la sumisión. Tanto los golpes, como la desesperanza, los desengaños, los atropellos y el desencanto ante la imposibilidad de tener una existencia más digna y distinta, han llevado a soportar con resignación la carga histórica, los fracasos, a la vez que nos han dejado en el desierto con las cadenas puestas, única posibilidad para seguir vivos.

De manera que en Colombia tenemos la sensación de que el Estado es un enemigo del ciudadano, lo que imposibilita la confianza entre todos, sin lograr construir símbolos y narrativas solidarias. La constante renovación de la Regeneración sectaria y conservadora retarda día a día nuestra apertura ciudadana ético-política, próxima a una democracia real y participativa. Siendo hombres y mujeres de extremos, nos alimentamos de los fanatismos en todos los campos: deportivos, religiosos, morales, políticos, culturales y de engaños nacionales. En este país, los militares y policías aún saludan ante las cámaras y micrófonos con la frase de "Dios y Patria"; a los niños de algunos colegios oficiales se les obliga a rezar el rosario y a escuchar clases de religión católica; nuestros mandatarios se persignan en público y evocan a la Virgen de Chiquinquirá y al Sagrado Corazón como se acostumbraba bajo la Regeneración; la libertad de expresión solo es formal y de papel, pues aún, soterradamente, se aplica el artículo 42 de la Constitución del 86 donde se proclamaba que "la prensa es libre en tiempos de paz, pero responsable con arreglo a las leyes, cuando atente contra la honra de las personas, la tranquilidad pública y el orden social". Todavía la censura simulada o directa a las voces de periodistas críticos, junto a su expulsión de los medios y su exilio, se gestan en Colombia como en la época de Rafael Núñez.

Bajo estas tragicomedias históricas, en torno a la espectacularización de las masacres y del tiro al blanco como deporte nacional, nuestro país se edifica con una cultura sin memoria, demasiado parroquial, donde el asesinato, la trampa, el engaño, la envidia, la cizaña, la sumisión, se han introducido como rituales cotidianos en nuestra canasta familiar.

El resultado de todos estos procesos es un sistema, citando a Octavio Paz, "Patrimonialista", donde "el jefe de gobierno - Príncipe o Virrey, caudillo o presidente - dirige el Estado y a la Nación como una extensión de su patrimonio particular, esto es, como si fuera su casa" (PAZ, 1998: p. 169). Y no otras condiciones son las que se hacen visibles en Colombia: una burguesía que no asimiló - o asimiló mal - el espíritu moderno; una clase dominante semi-feudal, mafiosa y hacendaria, un dominio casi absoluto por parte del imperio y una parte de la intelectualidad colaboracionista, nada crítica, más bien coexistiendo pacíficamente en medio de las ruinas. 
Esa es la Colombia que inventamos, la Colombia que padecemos; la Colombia que desde hace décadas vive de sus miedos y sumisiones; el país que se cuida de todos y a todo teme, el que Fernando Vallejo nos describe en su novela Los días azules:

En Colombia, por si usted va, sobran ladrones. ¡Con tanta ley y tanto desocupado! Uno va en un bus y lo bolsea un carterista; se baja, y le arranca el sombrero un ciclista. Si a usted lo atropella un carro, le cae una multitud a ver en qué lo pueden aligerar. Todo en Colombia se lo roban: se roban los postes del teléfono, se roban los cables de la luz; se roban las tejas de las casas, se roban un automóvil, se roban una gallina, se roban un marrano (...). En esta tierra mía de fracaso acumulado se maneja así: se ve a un peatón cruzando la calle y se acelera a ver si le alcanza a dar, como a conejo encandilado en noche oscura y ebria de carretera. -iQuitate hijueputa!- le grita desde el carro el chofer, y se quita o muere. (VALLEJO, 2012: págs. 149 y 175).

\section{BIBLIOGRAFÍA}

CRUZ KRONFLY Fernando. (2016). “La Aldea Encantada”. Estéticas en Colombia Siglo XX. Bogotá. Comp. Carlos Fajardo Fajardo, ediciones Desde Abajo.Págs. 215-236.

GAITÁN DURÁN Jorge. (1999). La revolución invisible. Bogotá, Ariel.

GONZÁLEZ Fernando, (1976). Viaje a pie. Bogotá, Editorial Bedout.

MORENO DURÁN R. H. (1987). “Por una escritura disidente”. Magazín Dominical, El Espectador, Bogotá, Colombia. 26 de julio, pp. 14-18.

REYES Emma, (2013). Tercera edición. Memoria por correspondencia. Laguna libros, Fundación arte vivo Otero Herrera.

URIBE CELIS Carlos. (1992). La mentalidad del colombiano. Santafé de Bogotá, Ediciones Alborada.

URREGO Miguel Ángel. (2002). Intelectuales, Estado y Nación en Colombia. Bogotá, Universidad Central. VALLEJo Fernando, (2012). Los días azules. Bogotá: Planeta.

VARGAS VILA José María, (2000). Diario (de 1899 a 1932) Y la increíble historia de unas memorias codiciadas. Edición a cargo de Raúl Salazar Pazos. Barcelona, Ediciones Áltera.

VARGAS VILA José María. (1998). Pretéritas, Bogotá, Panamericana.

VIDAL Margarita. (1979, 5 de noviembre de 1979). Entrevista a Darío Echandía. Revista Cromos. Recuperado de http://www.cromos.com.co/especial-95/articulo-141846-celebre-entrevista-adario-echandia

WILLIAMS Raymond L. (1992). Novela y poder en Colombia. 1944-1987. Bogotá, Tercer Mundo Editores. ZULETA Estanislao (2016). "Elogio de la dificultad”. Estéticas en Colombia Siglo XX. Bogotá. Comp. 


\section{NOTAS}

1. Viaje a pie fue prohibido bajo pecado mortal por los obispos de Medellín y de Manizales. Transcribimos una de las cartas de prohibición: El Arzobispo de Medellín: NOS MANUEL JOSÉ CAYZEDO por la gracia de Dios y de la Santa Sede Arzobispo de Medellín Asistente al Solio Pontificio Constituidos por nuestro cargo pastoral en guardián de la fe y de las buenas costumbres [c.336], apremiados por el deber de alejar el peligro de perversión que traen las malas lecturas [c.1395] y habiendo sido denunciado ante Nos como gravemente nocivo el libro intitulado "Viaje a pie" cuyo autor es el doctor Fernando González. Después de haberlo sometido a examen y haberlo hallado prohibido a iure, porque ataca los fundamentos de la Religión y la moral con ideas evolucionistas, hace burla sacrílega de los dogmas de la fe, es blasfemo de Nuestro Señor Jesucristo y con sarcasmos volterianos se propone ridiculizar las personas y las cosas santas, trata de asuntos lascivos y está caracterizado por un sensualismo brutal que respiran todas sus páginas. Decretamos: El libro del doctor Fernando González, "Viaje a pie”, está vetado por derecho natural y eclesiástico, y por tanto su lectura es prohibida bajo pecado mortal. El presente Decreto será leído en todas las iglesias y capillas de la ciudad arzobispal y publicado por la prensa para conocimiento de los fieles.Dado en Medellín, a 30 de diciembre de 1929Manuel José Arzobispo de Medellín

2. Podemos sintetizar el espíritu de la Regeneración y su manifestación en Colombia como el de la tradición que impone la clase terrateniente conservadora, acérrima defensora de la contrarreforma y el catolicismo españoles, con sus consecuencias de Estado confesional, que ataca al laicismo y a la educación laica. Su visión del mundo impone una lógica del respeto a los dogmas cristianos y una "igualdad de los hombres basada sobre categorías transcendentales y eternas", según palabras de Laureano Gómez. (Citado por Uribe Celis, La mentalidad del colombiano, 1992, p. 118). Todo lo que significa cambio o impulso a la modernidad es repudiado por la Regeneración: la revolución francesa, el liberalismo burgués, el proceso del capitalismo con su revolución industrial, la libertad, la igualdad, la fraternidad, como también todos los sistemas filosóficos surgidos desde y por la Modernidad. "El púlpito fue en todo el país el aparato reproductor de esta ideología, masiva y prioritariamente más activo hasta bien entrado el siglo" (Uribe Celis: 122).

3. Al decir del crítico norteamericano Raymond L. Williams, "De acuerdo a la retórica oficial, la Regeneración buscaba unidad nacional y lugar preponderante para la Iglesia Católica como institución. El presidente Núñez expresó la esencia de la Regeneración en el tan frecuentemente citado mensaje al Congreso de 1888: 'Pero para lo fundamental y permanente, los elementos cardinales serán el cultivo del sentimiento religioso, que regenera mostrando lo infinito, y la instrucción activamente propagada con la savia de ese mismo sentimiento' " (Williams, 1992, pp. 56-57).

4. “A diferencia de otros países, no se elaboró una reflexión filosófica o política ni se recreó simbólicamente la nación, simplemente se recurrió a una imagen que expresaba los valores de una elite y que no tenía nada que ver con la cultura ni con la realidad de nuestro país. Por ello en el periodo que estudiamos se renueva la imagen del 'cachaco' bogotano como tipo ideal nacional, $y$, paralelamente, se elabora una representación de lo popular desde una perspectiva racista y clasista" (URREGO, 2002: 57).

5. Así, por ejemplo, la llamada generación del Centenario (Centenario del grito de Independencia, 1810-1910) no generó ninguna ruptura con la tradición cultural ni política conservadora. Academicistas, neoclásicos e intelectualmente decimonónicos, apoyaron muy tímidamente los proyectos de la modernidad. Entre sus miembros se encuentran Enrique Olaya Herrera, el conservador Silvio Villegas, Luis Cano, el poeta Eduardo Castillo.

6. A pesar de que el analfabetismo hacia 1912 era del 83.1 por ciento y que en 1918 se redujo al 61 por ciento, "en las primeras décadas del siglo XX la poesía y la historia dominaban en los 
artículos de las revistas que se autodefinían como culturales o literarias. Si tomamos como ejemplo la revista Alpha, podemos encontrar que de los 440 artículos considerados, desde la edición número uno- que apareció en 1906- a la número 58-que se publicó en 1910- 125 fueron, en realidad, poemas; de los 103 artículos de la Revista Contemporánea (entre enero y septiembre de 1905), 32 fueron, efectivamente, poemas. Las temáticas centrales: el amor, la mujer y la muerte. De total de artículos de la revista Alpha, 36 correspondieron al tema del amor y 127 a la mujer. Esto no tendría nada de particular si dejamos de considerar que, en lo fundamental, estaban encaminados a dejar una moraleja, eran creados desde una reflexión moral" (URREGO, 2002: 78-79).

7. Las coincidencias son inmensas con la Colombia de hoy. Veamos la radiografía de finales del siglo XIX que realiza Vargas Vila en las siguientes líneas:"Se van a acabar los librepensadores y va haber quema de herejes. El Papa tiene aquí un hijo fidelísimo. Tenemos los Reverendos Padres Jesuitas; los conventos que la impiedad había quitado los padres, para cometer el sacrilegio de llenarlos de jardines y surtidores y balcones, volverán a ser casas de oración y en sus ventanas volverán a verse los poéticos tiestos con flores y los pajaritos enjaulados trinando alegremente. Ya no habrá tanto colegio Mazón, en que aprendían los muchachos esas groserías, que s e llaman lenguas extranjeras, y que no les sirven sino para leer malos libros, que aparta de Dios y de la Iglesia. Pero, en cambio habrá buenos conventos de Padres donde entrarán los niños de novicios, para enseñarles el camino al cielo (...). En la Universidad no se enseñarán ya ni Bentham, ni Tracy, ni Julio Simón, no ninguno de esos franceses herejes, sino las doctrinas del angélico Doctor, y los jóvenes ya no se ocuparán en resolver y meditar los grandes problemas filosóficos, ni esas vagabunderías sociales del progreso, y la miseria y el trabajo, pero se ocuparán con provecho sumo en estudiar los siete cielos, y lo que es aún más útil para la humanidad: la naturaleza de los ángeles. No se enseñará ya la filosofía de este maldito siglo XIX, sino la del siglo XIII, en que con tanto esplendor brilló Santo Tomás “(1998, págs... 181-182).

\section{RESÚMENES}

En este artículo se indaga cómo, desde la instauración de la llamada Regeneración, movimiento de ideología hispano-católica conservadora de finales del siglo XIX, Colombia no ha superado aquella tradición premoderna, acérrima defensora de las tradiciones, de la moral católica y de las instituciones hacendarias, llegando a constituirse en buena parte en un Estado casi confesional a pesar de la apertura que significó, en algunos aspectos, la Constitución de 1991. El texto aborda diferentes visiones de intelectuales y escritores colombianos del siglo XX que dieron cuenta de dicha condición político-cultural, a la cual el poeta Jorge Gaitán Durán denominó ya en 1959 «nuestro paternalismo feudal».

Dans cet article on s'inquérit de comment, depuis l'instauration de la Régéneration, mouvement d'idéologie hispano-cathólique conservatrice de la fin du XIXème siècle, la Colombie n'a pas encore dépassé la tradition prémoderne caracterisée par être une intrinsigeant défenseur des traditions, de la morale cathólique et des institutions du trésor publique, en se constituant dans un État presque confesionnel malgré l'ouverture qui a signifié, en quelques aspects, la Constitution de 1991. Le texte aborde des divers points de vue des intelectuels et des écrivains colombiens du XXème siècle qui ont montré la condition politique et culturelle à laquelle le poète Jorge Gaitán Durán a nommé en 1959 «Notre paternalisme féodal». 
ÍNDICE

Mots-clés: hégémonie conservatrice, régénération, hispano-catholicisme, violence partisane, état libéral, modernité

Palabras claves: conservadora, regeneración, hispano-catolicismo, violencia partidista, estado liberal, modernidad

\section{AUTOR}

\section{CARLOS FAJARDO}

Magíster y Doctor en Literatura. Poeta, investigador y ensayista. Profesor Asociado de la Maestría en Comunicación-Educación de la Facultad de Ciencias y Educación, Universidad Distrital Francisco José de Caldas, Bogotá. Es colaborador del Periódico Le Monde diplomatique. Director de la "Colección Pensamiento Estético Siglos XX y XXI" editada por Desde abajo y Le Monde diplomatique, Colombia. Autor de varios libros, entre ellos: "Tierra de Sol" y "Navíos de Caronte". 